\title{
Polycondensation of di- and tetrasubstituted dibromobenzenes for synthesis of poly(p-phenylene)s having alkoxy groups and gas permeability of membranes
}

\author{
Toshikazu Sakaguchi, Takuya Nakano, Shinichi Tominaga and Tamotsu Hashimoto
}

Polymerizations of di-substituted $p$-dibromobenzenes [with the following substituents: linear alkoxy groups (1a-d), branched alkoxy groups (1e and 1f), and methoxyethoxy (1g)] and tetrasubstituted p-dibromobenzenes [with the following substituents: butoxy (1h) as well as butoxy and methyl (1i)] were investigated with a Ni catalyst. Monomers having linear alkoxy groups polymerized to give relatively high molecular weight polymers $\left(M_{n}=40300-49600\right)$ in good yields. However, the molecular weights and yields of the polymers having branched alkoxy groups were relatively low because of the steric effect of branched alkoxy chains. The methoxyethoxy group-containing monomer afforded an oligomer with an $M_{n}$ of 666 . The coupling reaction of tetrasubstituted $p$-dibromobenzenes occurred at a very-low level because of the steric hindrance of the tetra substituents. Polymers 2a-f exhibited high thermal stability, and the decomposition temperatures were higher than $350^{\circ} \mathrm{C}$. From the differential scanning calorimetry thermograms, $2 \mathrm{~b}-\mathrm{d}$ and $2 \mathrm{f}$ showed melting of crystallites $\left(T_{\mathrm{m}}: 120^{\circ} \mathrm{C}\right.$ for $2 \mathrm{~b}, 95^{\circ} \mathrm{C}$ for $2 \mathrm{c}$, $100^{\circ} \mathrm{C}$ for $2 \mathrm{~d}$ and $16^{\circ} \mathrm{C}$ for $\left.2 \mathrm{f}\right)$, and $2 \mathrm{a}$ and $2 \mathrm{e}$ showed glass transitions $\left(T_{\mathrm{g}}: 155^{\circ} \mathrm{C}\right.$ for $2 \mathrm{a}, 65^{\circ} \mathrm{C}$ for $\left.2 \mathrm{e}\right)$. The freestanding membranes could be prepared by the hot-press method from the crystalline polymers $(2 \mathrm{~b}-\mathrm{d})$. These membranes exhibited relatively high gas permeability, and the oxygen permeability coefficients were 14.8-27.8 barrer, higher than those previously reported for poly( $p$-phenylene)s having ester substituents.

Polymer Journal (2015) 47, 362-368; doi:10.1038/pj.2015.11; published online 11 March 2015

\section{INTRODUCTION}

Gas separation membranes have attracted substantial attention because they can save energy and costs in the separation process. ${ }^{1-5}$ As a separation membrane material, poly(substituted acetylene)s ${ }^{6-8}$ have been studied because of their high gas permeability. The primary chains of these polymers are composed of alternating double bonds, and they are rigid and restricted in rotation. When these polymers possess spherical bulky substituents (for example, $\mathrm{SiMe}_{3}, t-\mathrm{Bu}, \mathrm{CF}_{3}$ ), the membranes typically have large free volume because of the steric repulsion of the bulky substituents. For example, poly (diphenylacetylene) having $\mathrm{SiMe}_{3}$ exhibits high gas permeability but low permselectivity. ${ }^{9}$ Carbon molecular-sieve membranes and polymers of intrinsic microporosity have been developed as new types of gas separation membranes, and they have been reported to show high performance in gas separation. ${ }^{10-13}$ There are a few polymers displaying a sufficient performance for practical applications, and the design and synthesis of novel polymers are important from an industrial viewpoint.

Poly(p-phenylene) is the simplest aromatic polymer, possessing a linear and rigid backbone. Thus, poly( $p$-phenylene)s possibly exhibit a high gas permeability and are interesting materials for gas separation membranes. Unsubstituted poly(p-phenylene) is insoluble in all organic solvents, but the incorporation of appropriate substituents can render poly( $p$-phenylene) soluble. ${ }^{14}$ Soluble poly( $p$-phenylene)s with substituents are synthesized by homo- or cross-coupling reactions that are typically nickel- or palladium-catalyzed. ${ }^{15}$ Among these reactions, the Yamamoto coupling reaction using a $\mathrm{Ni} / \mathrm{Zn}$ catalyst afforded relatively high molecular weight ester-substituted poly ( $p$-phenylene)s. ${ }^{16,17}$ We reported the gas permeability of membranes of ester-substituted poly( $p$-phenylene)s obtained by the Yamamoto coupling reaction for the first time. We also revealed that estersubstituted poly( $p$-phenylene)s exhibited relatively high gas permeability, and the gas permeability increased as the length of the alkyl side chains increased. ${ }^{18}$

In the present study, we targeted di- and tetrasubstituted poly ( $p$-phenylene)s, which are predicted to have more twisted main chains than monosubstituted poly( $p$-phenylene)s. An increasing number of substituents on a benzene ring may induce high gas permeability because packing of the polymer chain is prevented by the twisted main chain and steric repulsion of the substituents. Alkoxy di-substituted poly( $p$-phenylene)s have been synthesized by oxidative coupling of dialkoxybenzene ${ }^{19-21}$ and the coupling of mono-Grignard dialkoxyhalobenzene with a $\mathrm{Ni}$ catalyst. ${ }^{22-25}$ Yokozawa and co-workers ${ }^{26}$ have reported the synthesis of dihexyloxy poly(p-phenylene) with a controlled molecular weight and low polydispersity by a controlled polycondensation, called catalyst-transfer polycondensation. 
<smiles>[R20]Oc1cc(Br)c([R20])cc1Br</smiles><smiles>CCC(O)CCC(C)OCC(C)(C)C</smiles><smiles>CC(C)CO</smiles><smiles>CC(C)COCC(C)CC(C)C</smiles>
1a-g 2a-g<smiles>CCCCC(CC)CO</smiles><smiles>CCOCCO</smiles><smiles>CCCCOc1c(Br)c(OCCCC)c(OCCCC)c(Br)c1OCCCC</smiles><smiles>CCCCOc1c(Br)c(OCCCC)c(OCCCC)c(OCCCC)c1OCCl</smiles><smiles>CCCCOc1c(OCCCC)c(OCCCC)c(C(C)(C)C)c(OCCCC)c1OCCCC</smiles><smiles>CCCCOc1c(C)c(Br)c(OCCCC)c(C)c1Br</smiles>

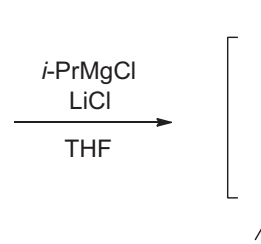<smiles>CCCCOc1c(C)c(Br)c(OCCCC)c(C)c1Cl</smiles><smiles>CCCCOc1c(C)c(OCCCC)c(C(C)(C)C)c(C)c1OCCCC</smiles>

Scheme 1 Synthesis of ether-substituted poly( $p$-phenylene)s by Ni-catalyzed polymerization.<smiles>[R20]c1cc(Br)c([R])cc1Br</smiles><smiles>CCCCOc1cc(OCCCC)c(OCCCC(C)(C)C)cc1OCCCC</smiles><smiles>CCCCOc1cc(C)c(OCCCC)cc1C</smiles>

Scheme 2 Synthesis of monomers $1 \mathbf{a}-\mathbf{i}$.

The polymerization using $\mathrm{Ni}$ (dppe) $\mathrm{Cl}_{2}$ (dppe = 1,2-bis-(diphenylphosphino)ethane) proceeds faster than that using other Ni catalysts and affords dihexyloxy poly( $p$-phenylene) with high molecular weight. ${ }^{26}$ Therefore, we synthesized poly(p-phenylene)s having various substituents by catalyst-transfer polycondensation using $\mathrm{Ni}(\mathrm{dppe}) \mathrm{Cl}_{2}$, and the gas permeability was studied (Scheme 1).

\section{EXPERIMENTAL PROCEDURE}

\section{Measurements}

The molecular weight distributions of the polymers were measured by gel permeation chromatography (GPC) in chloroform (at a $1.0 \mathrm{ml} \mathrm{min}{ }^{-1}$ flow rate) at $40{ }^{\circ} \mathrm{C}$ on a Shimadzu LC-10AD chromatograph (Shimadzu Co., Kyoto, Japan) equipped with three polystyrene gel columns (Shodex K-804 L, K-805 L, K-807 L) and a Shimadzu RID-6 A refractive index detector (Shimadzu, Co.). The number-average molecular weight $\left(M_{\mathrm{n}}\right)$ and polydispersity ratio [weightaverage molecular weight/number-average molecular weight $\left.\left(M_{\mathrm{w}} / M_{\mathrm{n}}\right)\right]$ were calculated from the chromatograms based on a polystyrene calibration. The ${ }^{1} \mathrm{H}$ $(500 \mathrm{MHz})$ and ${ }^{13} \mathrm{C}(125 \mathrm{MHz}) \mathrm{NMR}$ spectra were recorded on a Jeol LA-500 instrument (Jeol Ltd., Tokyo, Japan) in $\mathrm{CDCl}_{3}$ at room temperature. Thermogravimetric analyses were conducted with a Rigaku TG-DTA 8078G1 instrument (Rigaku Co., Tokyo, Japan) under $\mathrm{N}_{2}$ at a $10^{\circ} \mathrm{C} \mathrm{min}^{-1}$ heating rate. The thermal decomposition temperature was defined as the temperature at which a $5 \%$ weight loss of the sample occurs. Differential scanning calorimetry was 
Table 1 Results of polymerization of $1 \mathrm{a}-\mathrm{i}^{\mathrm{a}}$

\begin{tabular}{|c|c|c|c|c|c|}
\hline Entry & Monomer & $\mathrm{Ni}($ dppe $) \mathrm{Cl}_{2}, \mathrm{~mm}$ & Yield, \% & $M_{n}^{c}$ & $M_{w} / M_{n}{ }^{\mathrm{c}}$ \\
\hline 1 & 1a & 6.3 & 65 & 44900 & 1.81 \\
\hline 2 & $1 \mathrm{~b}$ & 6.3 & 55 & 49600 & 1.88 \\
\hline 3 & $1 c$ & 6.3 & 45 & 43100 & 2.40 \\
\hline 4 & $1 d$ & 6.3 & 62 & 40300 & 1.90 \\
\hline 5 & $1 \mathrm{e}$ & 6.3 & 27 & 16400 & 2.26 \\
\hline 6 & 1e & 0.77 & 12 & 38600 & 1.99 \\
\hline 7 & $1 f$ & 6.3 & 11 & 14700 & 2.84 \\
\hline 8 & $1 \mathrm{~g}$ & 6.3 & 87 & 666 & 3.57 \\
\hline 9 & $1 h^{d}$ & 6.3 & - $^{\mathrm{e}}$ & $354^{f}$ & $1.15^{\mathrm{f}}$ \\
\hline 10 & $1 \mathrm{i}^{\mathrm{d}}$ & 6.3 & $-^{\mathrm{e}}$ & $480^{f}$ & $1.04^{f}$ \\
\hline
\end{tabular}

aln THF at rt for $96 \mathrm{~h} ;[\mathrm{M}]_{0}=1.0 \mathrm{~m},[i-\mathrm{PrMgCl}]=1.0 \mathrm{~m}$.

${ }^{\mathrm{b}}$ Methanol insoluble product.

cMeasured by GPC (polystyrene calibration).

$\mathrm{d}[\mathrm{M}]_{0}=0.32 \mathrm{M},[i-\operatorname{PrMgCl}]=0.32 \mathrm{M}$.

e Methanol insoluble product was not obtained.

fWhole sample without purification after polymerization.

performed with a Rigaku Thermo Plus DSC 82301 instrument (Rigaku Co.). The temperature range was -100 to $+200{ }^{\circ} \mathrm{C}$, and the heating and cooling rates were $5^{\circ} \mathrm{C} \mathrm{min}{ }^{-1}$. During the measurement, the sample was purged by nitrogen gas. Gas permeability coefficients were measured with a Tsukubarikaseiki $\mathrm{K}-315-\mathrm{N}$ gas permeability apparatus (Tsukubarikaseiki Co., Ibaraki, Japan) at $25{ }^{\circ} \mathrm{C}$ under 1 atm upstream pressure. The permeability coefficient $(P)$ expressed in barrer units $\left(1\right.$ barrer $=10^{-10} \mathrm{~cm}^{3}$ (STP) $\mathrm{cm} \mathrm{cm}^{-2} \mathrm{~s}^{-1} \mathrm{~cm} \mathrm{Hg}^{-1}$ ) was calculated from the slope of the steady-state line.

\section{Materials}

Hydroquinone, 2,5-dimethylbenzoquinone, 2,5-dihydroxybenzoquinone, 1-bromobutane, 1-bromohexane, 1-butanol, bromine, palladium/carbon (Pd $10 \%)$, dichloro [1,2-bis(diphenylphosphino)ethane] nickel (II) and common organic solvents were commercially obtained from Wako Pure Chemicals, Ind., Ltd, Tokyo, Japan and used without further purification. 1-Bromooctane, 1bromodecane, 3-bromopentane, 1-bromo-2-ethylhexane, and isopropyl magnesium chloride/ lithium chloride $(1.0 \mathrm{M}$ in tetrahydrofuran) were purchased from Tokyo Kasei Kogyo, Ind., Ltd, Tokyo, Japan and used without further purification. Monomers $(\mathbf{1} \mathbf{a}-\mathbf{i})$ were synthesized by alkylation and bromination as shown in Scheme 2. Synthesis of monomers $\mathbf{1} \mathbf{a}-\mathbf{d}^{26-28}$ and $\mathbf{1} \mathbf{f}-\mathbf{h}^{29-31}$ has been previously reported, and monomers $1 \mathbf{e}$ and $\mathbf{l i}$ were newly synthesized in the present study. The details of the procedures and analytical data are described below.

\section{Synthesis of 1,4-dibromo-2,5-di(3-pentoxy)benzene (1e)}

A 500-ml three-necked flask was equipped with a reflux condenser, a dropping funnel, a three-way stopcock, and a magnetic stirring bar. After the flask was flushed with nitrogen, hydroquinone $(16.5 \mathrm{~g}, 0.150 \mathrm{~mol}), \mathrm{K}_{2} \mathrm{CO}_{3}(51.8 \mathrm{~g}, 0.375$ mol) and $\mathrm{N}, \mathrm{N}$-dimethylformamide $(300 \mathrm{ml})$ were added into the flask, and the mixture was stirred at $60^{\circ} \mathrm{C}$ for $60 \mathrm{~min}$. After cooling the flask to room temperature, 3-bromopentane $(45.3 \mathrm{~g}, 0.300 \mathrm{~mol})$ was slowly added to the flask through the dropping funnel at room temperature, and the mixture was stirred at $80^{\circ} \mathrm{C}$ for $24 \mathrm{~h} . \mathrm{CHCl}_{3}(500 \mathrm{ml})$ was added to the mixture, and $\mathrm{K}_{2} \mathrm{CO}_{3}$ was filtered off. The solution was washed with water and then dried over anhydrous sodium sulfate. The dialkoxylated product was purified by silica gel column chromatography (eluent: hexane/ethyl acetate $=9: 1)$ as a colorless liquid $(25.2 \mathrm{~g}$, $0.101 \mathrm{~mol}$, yield $67 \%)$.

To a $500-\mathrm{ml}$ three-necked round-bottom flask equipped with a magnetic stirring bar and dropping funnel was added 1,4-di(3-pentoxy)benzene (20.2 g, $0.0805 \mathrm{~mol})$ and $250 \mathrm{ml} \mathrm{CHCl}$. A solution of bromine $(12 \mathrm{ml}, 0.242 \mathrm{~mol})$ in $\mathrm{CHCl}_{3}(50 \mathrm{ml})$ was slowly added to the flask through the dropping funnel at $0^{\circ}$ $\mathrm{C}$, and the mixture was stirred for $24 \mathrm{~h}$ at room temperature. The reaction mixture was washed with sodium hydrogen sulfite and water. The solution was dried over anhydrous sodium sulfate and then concentrated at reduced pressure. The crude product was purified by silica gel column chromatography (eluent: hexane/ethyl acetate $=9 / 1)$ to give $1 \mathrm{e}(27.9 \mathrm{~g}, 0.0684 \mathrm{~mol}, 85 \%)$ as a white solid. Mp: $57.0-58.0{ }^{\circ} \mathrm{C}$, purity: $>99 \%\left({ }^{1} \mathrm{H}\right.$ NMR). ${ }^{1} \mathrm{H}$ NMR $\left(\mathrm{CDCl}_{3}\right.$, p.p.m.): 7.07 (s, 2H, Ar), 4.03 (quint, $J=7.5 \mathrm{~Hz}, 2 \mathrm{H}, \mathrm{OCH}$ ), 1.69 (quint, $\left.J=7.5 \mathrm{~Hz}, 8 \mathrm{H}, \mathrm{OCHCH}_{2}\right)$, and $0.97\left(\mathrm{t}, J=7.5 \mathrm{~Hz}, 12 \mathrm{H}, \mathrm{OCHCH}_{2} \mathrm{CH}_{3}\right)$. ${ }^{13} \mathrm{C}$ NMR ( $\mathrm{CDCl}_{3}$, p.p.m.): 149.6, 120.3, 112.3, 83.2, 25.8, 9.48. Anal. Calcd for $\mathrm{C}_{16} \mathrm{H}_{24} \mathrm{Br}_{2} \mathrm{O}_{2}$ : C, 47.08; H, 5.93. Found: C, 46.86; H, 5.90.

\section{Synthesis of 1,4-dibromo-2,5-dibutoxy-3,6-dimethylbenzene (1i)}

A 500-ml three-necked flask was equipped with a three-way stopcock and a magnetic stirring bar. After the flask was flushed with nitrogen, 2,5-dimethylbenzoquinone $(5.0 \mathrm{~g}, 0.037 \mathrm{~mol})$, palladium/carbon (Pd 10\%, $1.3 \mathrm{~g}, 0.012 \mathrm{~mol})$ and ethyl acetate $(200 \mathrm{ml})$ were added into the flask. Hydrogen gas $(\sim 2.0 \mathrm{l})$ flowed into the flask, and then the mixture was stirred at room temperature for $24 \mathrm{~h}$ under $\mathrm{H}_{2}$ atmosphere. Palladium/carbon was filtered off, and the solution was evaporated under reduced pressure. The obtained compound (2,5-dimethylhydroquinone) was used for alkylation without further purification.

Alkylation and bromination of 2,5-dimethylhydroquinone were performed according to the method previously described. Mp: $73.0-74.0^{\circ} \mathrm{C}$, purity: $>99 \%$ $\left({ }^{1} \mathrm{H}\right.$ NMR $) .{ }^{1} \mathrm{H}$ NMR $\left(\mathrm{CDCl}_{3}\right.$, p.p.m.): 3.81 (t, $\left.J=6.6 \mathrm{~Hz}, 4 \mathrm{H}, \mathrm{OCH}_{2}\right), 2.38$ (s, $6 \mathrm{H}, \mathrm{Ar}-\mathrm{CH}_{3}$ ), 1.82 (quint, $J=6.6 \mathrm{~Hz}, 4 \mathrm{H}, \mathrm{OCH}_{2} \mathrm{CH}_{2}$ ), 1.55 (sext, $J=7.4 \mathrm{~Hz}$, $\left.4 \mathrm{H}, \mathrm{OCH}_{2} \mathrm{CH}_{2} \mathrm{CH}_{2}\right), 0.99\left(\mathrm{t}, J=7.4 \mathrm{~Hz}, 6 \mathrm{H}, \mathrm{OCH}_{2} \mathrm{CH}_{2} \mathrm{CH}_{2} \mathrm{CH}_{3}\right),{ }^{13} \mathrm{C} \mathrm{NMR}$ ( $\mathrm{CDCl}_{3}$, p.p.m.): 151.2, 131.1, 120.0, 72.9, 32.1, 19.3, 17.4, 13.9. Anal. Calcd for $\mathrm{C}_{16} \mathrm{H}_{24} \mathrm{Br}_{2} \mathrm{O}_{2}$ : C, 47.08; H, 5.93. Found: C, 46.91; H, 5.89.

\section{Polymerization}

Monomer 1a $(0.76 \mathrm{~g}, 2.0 \mathrm{mmol})$ was placed into a glass tube equipped with a three-way stopcock and a magnetic stirring bar under dry nitrogen and was then dissolved in dry tetrahydrofuran $(2.0 \mathrm{ml})$. Isopropyl magnesium chloride/ lithium chloride ( $1.0 \mathrm{M}$ in tetrahydrofuran, $2.0 \mathrm{ml}, 2.0 \mathrm{mmol}$ ) was slowly added to the solution, and the mixture was stirred at room temperature for $24 \mathrm{~h} . \mathrm{Ni}$ (dppe) $\mathrm{Cl}_{2}(6.6 \mathrm{mg}, 0.0125 \mathrm{mmol})$ and dry tetrahydrofuran $(2 \mathrm{ml})$ were placed in another tube equipped with a three-way stopcock and a magnetic stirring bar. This catalyst solution was added to the monomer solution, and the mixture was stirred at room temperature for $72 \mathrm{~h} . \mathrm{CHCl}_{3}(200 \mathrm{ml})$ was added, and the solution was washed three times with $1 \mathrm{~N} \mathrm{HCl}$ aq. The formed polymer was isolated by precipitation into a large excess of methanol, and its yield was determined gravimetrically.

\section{Membrane preparation}

Polymer membranes (thickness $\sim 150-200 \mu \mathrm{m}$ ) were prepared by molding the powder polymers with a hot-press apparatus (As One AH-2003) at $100-150^{\circ} \mathrm{C}$ and 5-20 MPa for $1 \mathrm{~h}$. Before the gas permeability measurement, the membranes were dried under vacuum $(<0.05 \mathrm{~mm} \mathrm{Hg})$ for $24 \mathrm{~h}$.

\section{Density of polymer membrane}

The densities of the membranes were determined by hydrostatic weighing using a Mettler Toledo balance (Mettler Toledo Inc., Tokyo, Japan) and a density determination kit. In this method, a liquid with known density $\left(\rho_{0}\right)$ is required, and the membrane density $(\rho)$ is given by the following equation:

$$
\rho=\rho_{0} \times M_{\mathrm{A}} /\left(M_{\mathrm{A}}-M_{\mathrm{L}}\right)
$$

where $M_{\mathrm{A}}$ is the membrane weight in air, and $M_{\mathrm{L}}$ is the membrane weight in the auxiliary liquid. Aqueous sodium nitrate was used as the auxiliary liquid.

\section{RESULTS AND DISCUSSION}

\section{Polymerization}

The polymerizations of monomers $\mathbf{1 a}-\mathbf{i}$ were performed using $\mathrm{Ni}$ (dppe) $\mathrm{Cl}_{2}$ in tetrahydrofuran, and the results are summarized in Table 1 . The polymerization of $\mathbf{1 a}$ with a $n$-butoxy group as a side chain provided polymer $(\mathbf{2 a})$ in $65 \%$ yield, with a number-average molecular weight $\left(M_{\mathrm{n}}\right)$ of 44900 (entry 1). The polymerizations of monomers 1b-1d with linear alkyl chains ( $n$-hexyloxy, $n$-octyloxy and $n$-decyloxy) proceeded in a similar manner, and polymers $\mathbf{2} \mathbf{b}-\mathbf{2} \mathbf{d}$ with $M_{\mathrm{n}}=40300-49600$ were obtained in good yields (entries 2-4). Yokozawa and coworkers have reported the polymerization of 2,5- 
dibromo-1,4-dihexyloxybenzene (1b) with $\mathrm{Ni}$ (dppe) $\mathrm{Cl}_{2}$ to afford polymer with $M_{\mathrm{n}}=12900,{ }^{26}$ which is lower than that of our polymer $\left(M_{\mathrm{n}}=49600\right)$. The polycondensation of the Grignard form of $\mathbf{1 b}$ with $\mathrm{Ni}$ (dppe $) \mathrm{Cl}_{2}$ proceeds via a chain-growth polymerization mechanism. ${ }^{26}$ Therefore, the difference in the polymer molecular weight originates from the difference in the mole ratios of the catalyst to monomer. The polymerization conditions used by Yokozawa and coworkers were as follows: $[\mathrm{M}]_{0}=0.20 \mathrm{M},[\mathrm{Ni}]=3.6 \mathrm{mM},[\mathrm{M}]_{0} /[\mathrm{Ni}]=$ 66.7. We polymerized at a higher concentration to obtain high molecular weight polymers. The conditions we used are the following: $[\mathrm{M}]_{0}=1.0 \mathrm{M},[\mathrm{Ni}]=6.3 \mathrm{mM},[\mathrm{M}]_{0} /[\mathrm{Ni}]=159$. In addition, the molecular weight distributions of our polymers were not narrow compared with the previous values, which can be accounted for by the difference in the monomer concentrations. It has been reported that the molecular weight distribution becomes broad when the polymerization is performed in the absence of $\mathrm{LiCl}$ because Grignard-type monomers aggregate. ${ }^{26}$ In our polymerization, the higher concentration of the monomer would cause aggregation, leading to the broader molecular weight distributions.

Monomers le and 1f, which have a branched alkoxy group, polymerized to give low-molecular-weight polymers in low yields compared with polymers having linear alkoxy groups (entries 5 and 7). The low polymerizability of $\mathbf{1 e}$ and $\mathbf{1 f}$ may be due to the steric hindrance of the branched side groups. To achieve a high molecular weight, the polymerization of 1 e was performed at low catalyst concentrations (entry 6). The $M_{\mathrm{n}}$ of $2 \mathrm{e}$ reached 38600 , but the yield

a

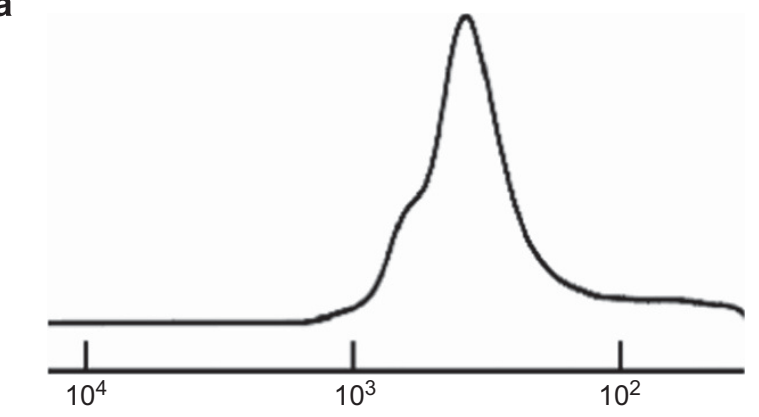

b
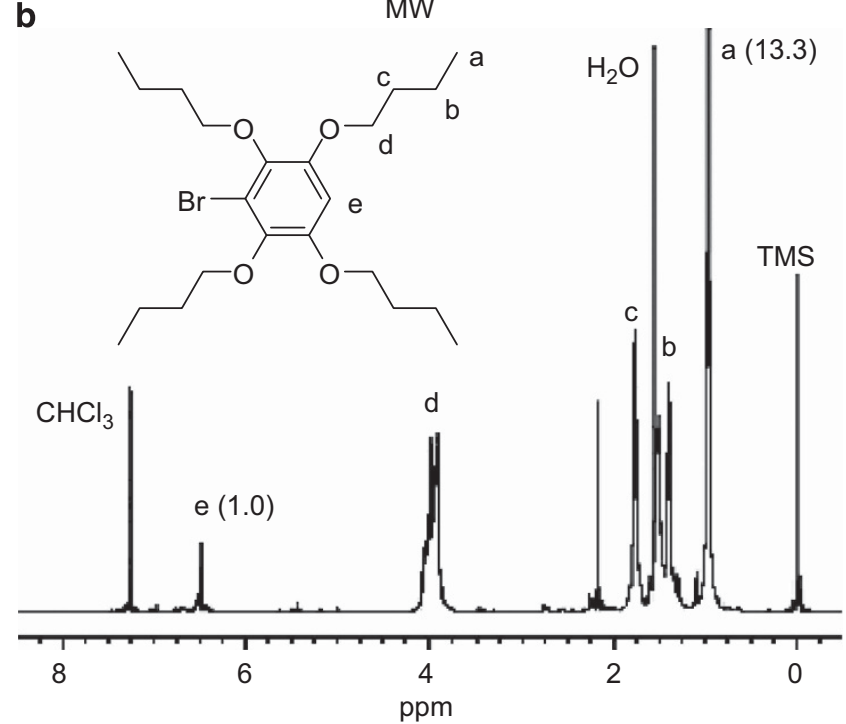

Figure 1 (a) GPC curve and (b) ${ }^{1} \mathrm{H}$ NMR spectrum in $\mathrm{CDCl}_{3}$ of the product obtained by polymerization of $\mathbf{l h}$. of the polymer was low. Monomer $\mathbf{1 g}$ bearing a methoxyethoxy group did not display a high degree of polymerization, and the oligomer was obtained (entry 8), most likely because the aliphatic ether oxygen was coordinated to the Ni catalyst.

The polymerizations of tetrasubstituted dibromobenzenes (1h and 1i) did not provide polymers (entries 9 and 10). The GPC chromatogram and ${ }^{1} \mathrm{H}$ NMR spectrum of polymerization product of $\mathbf{1 h}$ are shown in Figure 1. The peak top of the GPC curve corresponded to the molecular weight of the monomer, and the shoulder peak was observed on the left side of the main peak, suggesting that a small amount of dimer was produced. In the ${ }^{1} \mathrm{H}$ NMR spectrum, there was a singlet peak at 6.4 p.p.m. assigned to a proton connected to an aromatic carbon, which was not observed in the spectrum of monomer $\mathbf{l h}$. In the present polymerization, the monomer initially reacted with isopropyl magnesium chloride to afford the monoGrignard monomer, and then the mono-Grignard monomer was condensed by the Ni catalyst (Scheme 1). After polymerization, the magnesium chloride end groups were substituted by protons during the post-processing step. The mole ratio of dimer to monomer ([dimer] / [ monomer] $=r_{\mathrm{h}}$ ) was calculated from the integration ratio of peak a to peak $\mathbf{e}$ in the ${ }^{1} \mathrm{H}$ NMR spectrum using the following equation:

$$
r_{\mathrm{h}}=(13.3-12) /(24-13.3)=0.12
$$

a

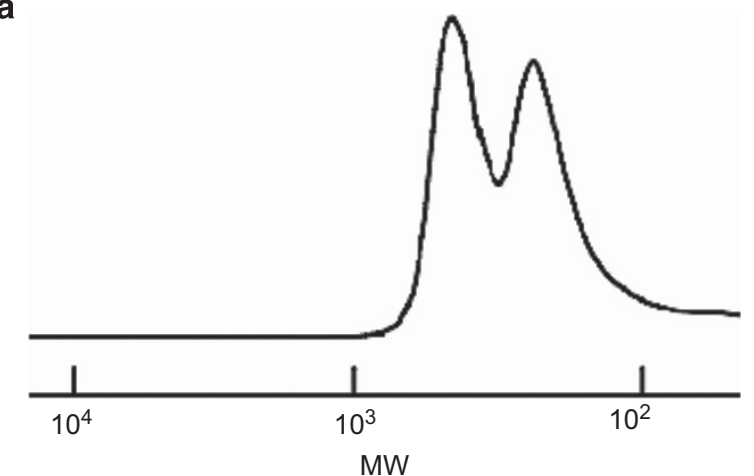

b

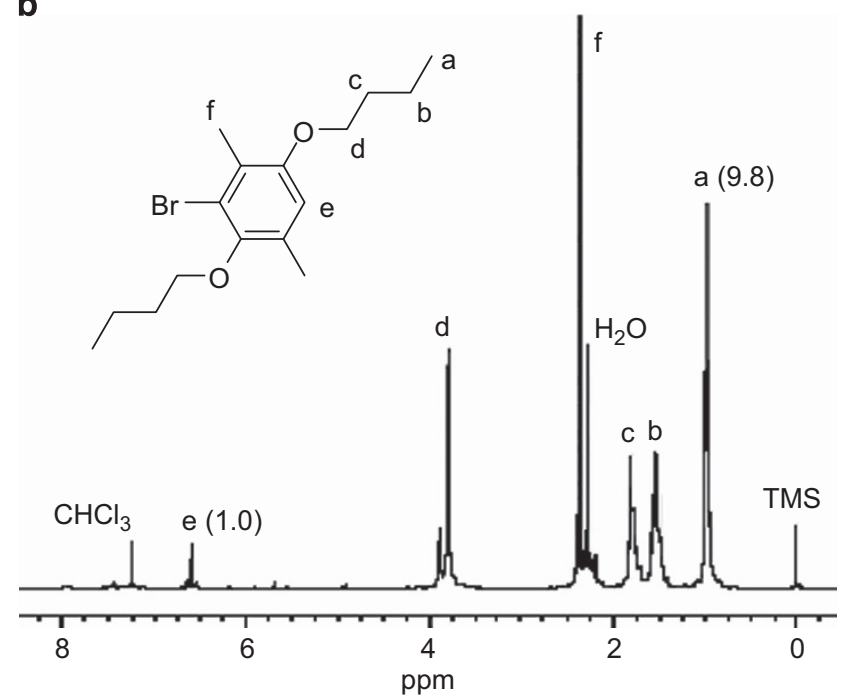

Figure 2 (a) GPC curve and (b) ${ }^{1} \mathrm{H}$ NMR spectrum in $\mathrm{CDCl}_{3}$ of the product obtained by polymerization of $\mathbf{1 i}$. 


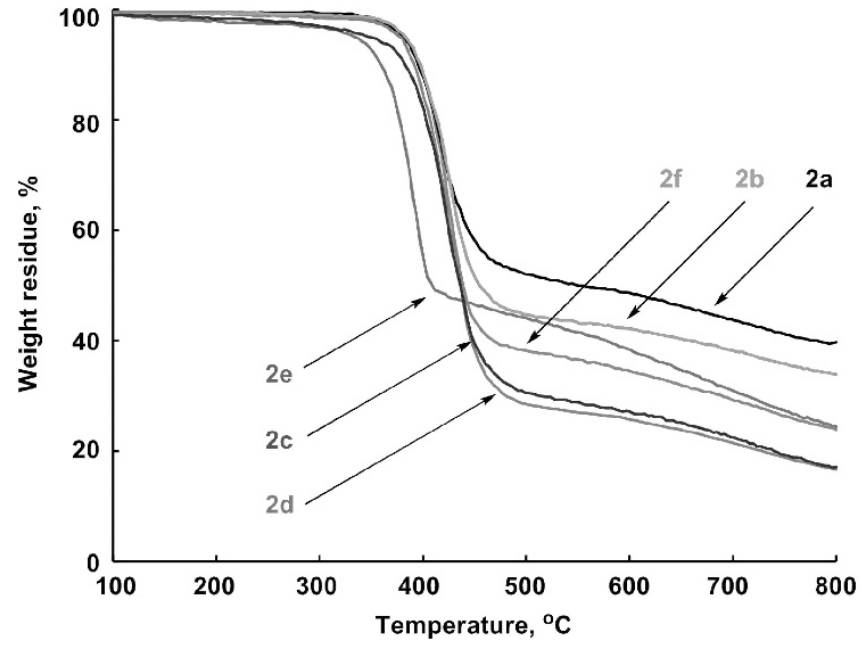

Figure 3 Thermogravimetric analysis curves of polymers 2a-f under $N_{2}$. A full color version of this figure is available at Polymer Journal online.

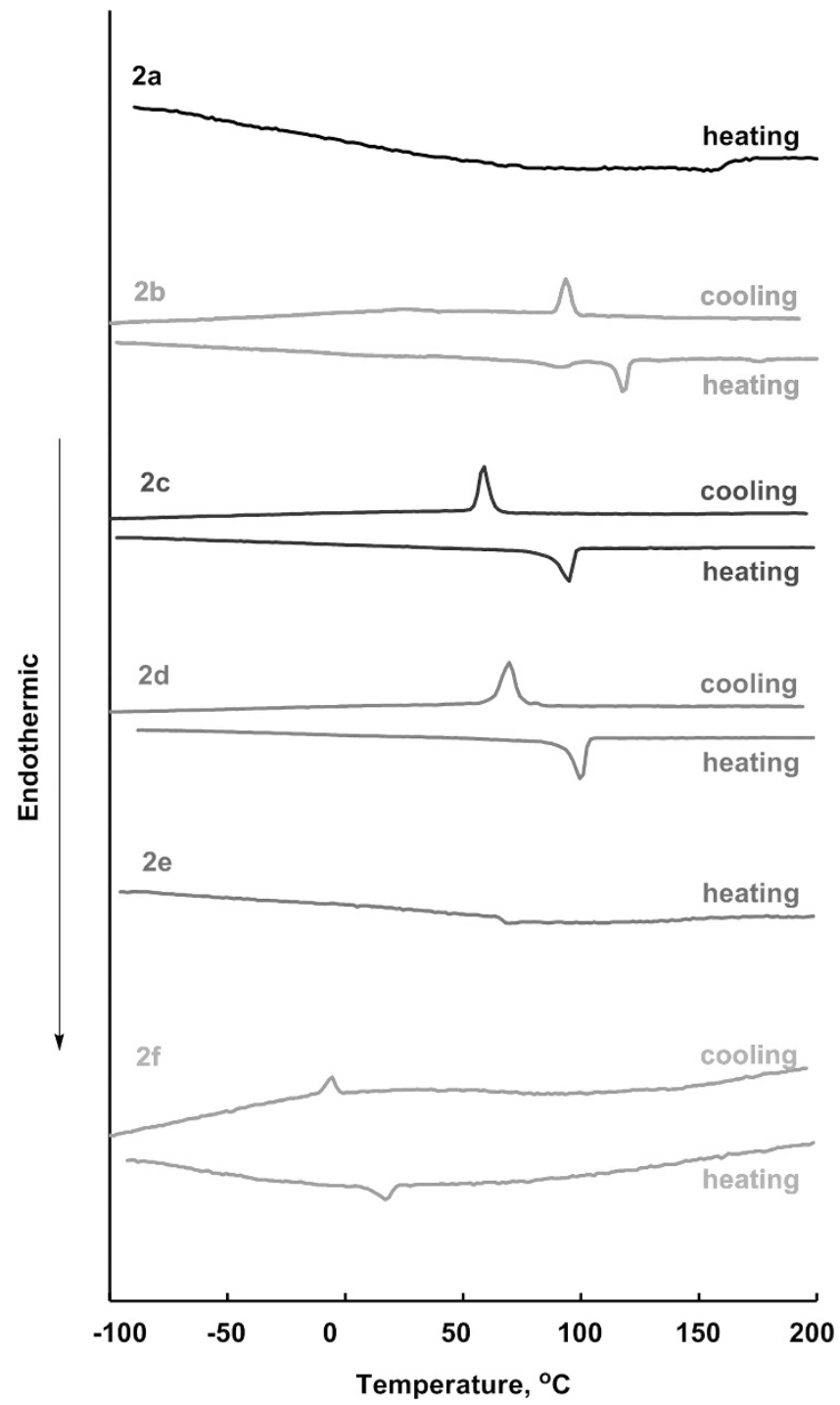

Figure 4 Differential scanning calorimetry thermograms of polymers 2a-f under $\mathrm{N}_{2}$ A full color version of this figure is available at Polymer Journal online.
Table 2 Solubility ability of the polymers ${ }^{a}$

\begin{tabular}{ccccccc}
\hline & Hexane & Toluene & $\mathrm{CHCl}_{3}$ & THF & Acetone & DMSO \\
\hline $2 \mathrm{a}$ & - & + & + & + & - & - \\
$\mathrm{2b}$ & - & + & + & + & - & - \\
$\mathrm{2c}$ & - & + & + & + & - & - \\
$2 \mathrm{~d}$ & - & + & + & + & - & - \\
$2 \mathrm{e}$ & - & + & + & + & - & - \\
$2 \mathrm{f}$ & - & + & + & + & - & - \\
$2 \mathrm{~g}$ & - & \pm & + & \pm & - & \pm \\
\hline
\end{tabular}

Abbreviation: DMSO, dimethylsulfoxide.

aSymbols: +soluble, \pm partially soluble, - insoluble.

Table 3 Density, gas permeability coefficients $(P)$ and permselectivity of membranes

\begin{tabular}{lcccccc}
\hline Membrane & $\begin{array}{c}\text { Density } \\
\left(\mathrm{gcm}^{-3}\right)\end{array}$ & $\begin{array}{c}\mathrm{PN}_{2} \\
(\text { barrer })^{\mathrm{a}}\end{array}$ & $\begin{array}{c}\mathrm{PO}_{2} \\
(\text { barrer })^{\mathrm{a}}\end{array}$ & $\begin{array}{c}\mathrm{PCO}_{2} \\
(\text { barrer })^{\mathrm{a}}\end{array}$ & $\mathrm{PO}_{2} / \mathrm{PN}_{2}$ & $\mathrm{PCO}_{2} / \mathrm{PN}_{2}$ \\
\hline 2b & 1.00 & 10.3 & 25.6 & 128 & 2.49 & 12.4 \\
2c & 1.02 & 5.86 & 14.8 & 72.8 & 2.53 & 12.4 \\
2d & 0.98 & 11.2 & 27.8 & 130 & 2.48 & 11.6 \\
\hline
\end{tabular}

a1 Barrer $=1 \times 10^{-10} \mathrm{~cm}^{3}($ STP $) \mathrm{cm} /\left(\mathrm{cm}^{2} \mathrm{~s} \mathrm{cmHg}\right)$.

This result indicates that the first reaction with isopropyl magnesium chloride occurred, but the coupling reaction of the monoGrignard monomers did not appreciably proceed. The coupling reaction would be prevented by the steric hindrance of the substituents because monomer $\mathbf{1 h}$ has four $n$-butoxy groups.

Figure 2 shows the GPC chromatogram and ${ }^{1} \mathrm{H}$ NMR spectrum of polymerization product of $\mathbf{1 i}$. Two peaks were observed in the GPC chromatogram. The $M_{\mathrm{n}}$ of the higher molecular weight peak was 480 , which corresponds approximately to the dimer of $\mathbf{1 i}$. The other peak corresponded to the molecular weight of the monomer. The mole ratio of dimer to monomer $\left(r_{\mathrm{i}}\right)$ was calculated from the ${ }^{1} \mathrm{H}$ NMR spectrum using the following equation:

$$
r_{\mathrm{i}}=(9.8-6) /(12-9.8)=1.73
$$

The four substituents of monomer $\mathbf{i}$ are not bulkier than those of monomer $\mathbf{h}$; thus, a higher dimer ratio was generated compared with monomer $\mathbf{h}$. However, the polymerization of the four substituted p-bromobenzene monomer produced no polymer with a higher degree of polymerization than a trimer.

\section{Thermal property and solvent solubility}

The thermal stability of polymers $2 \mathbf{a}-\mathbf{f}$ in $\mathrm{N}_{2}$ was evaluated by thermogravimetric analyses (Figure 3). Thermal decomposition temperatures ( $5 \%$ weight loss) of all of the polymers were higher than $350^{\circ} \mathrm{C}$, indicating good thermal stability. For $\mathbf{2 a}, \mathbf{2} \mathbf{b}, \mathbf{2 d}$ and $\mathbf{2} \mathbf{f}$, the weight losses began at $\sim 370^{\circ} \mathrm{C}$, substantially decreased until $\sim 480^{\circ} \mathrm{C}$, and then only slightly decreased. The decomposition temperatures of $2 \mathrm{c}$ and $\mathbf{2 e}$ were relatively lower than those of the other polymers, but the weight loss patterns are similar to the other polymers. Based on the percentage of weight loss, it was found that the polymers first lose the alkoxy side groups, and then decomposition of the main chains occurred.

The differential scanning calorimetry thermograms on the second heating or cooling scan of $\mathbf{2 a - f}$ are shown in Figure 4. Polymers 2a and 2e exhibited glass transitions at 155 and $65^{\circ} \mathrm{C}$, respectively. Polymers $\mathbf{2 b}, \mathbf{2 c}, \mathbf{2 d}$ and $\mathbf{2 f}$ showed crystallization on the cooling scans 
and melting of crystallites on the heating scans. These findings indicate that $\mathbf{2 a}$ and $\mathbf{2 e}$ are amorphous polymers, and $\mathbf{2} \mathbf{b}-\mathbf{d}$ and $\mathbf{2 f}$ are crystalline polymers. The melting temperatures of $\mathbf{2} \mathbf{b}-\mathbf{2} \mathbf{d}$, which have linear alkoxy chains, were at $\sim 100^{\circ} \mathrm{C}$, but that of $2 \mathrm{f}$, having branched alkoxy chains, was as low as $16^{\circ} \mathrm{C}$. The structures of poly ( $p$-phenylene)s in the present study are similar, but they exhibited different morphologies. The presence of an alkyl group in the side chain is an important factor for the formation of the crystalline phase. For example, poly( $p$-phenylenevinylene)s and poly(diphenylacetylene) $\mathrm{s}$ possessing long alkyl groups are crystalline polymers, whereas the polymers having shorter alkyl groups are amorphous polymers. ${ }^{32,33}$ This phenomenon is possibly the reason that $\mathbf{2 a}$, with the shortest alkyl side chains in the present study, is amorphous. However, the reason for the difference between $2 \mathrm{e}$ and $\mathbf{2 f}$ with branched alkyl groups is not clear at this stage.

The solubility properties of polymers $2 \mathbf{a}-\mathbf{g}$ were studied, and the results are summarized in Table 2. Polymers $2 \mathbf{a}-\mathbf{f}$ with linear and branched alkoxy chains showed the same solubility and completely dissolved in toluene, $\mathrm{CHCl}_{3}$, and tetrahydrofuran. The solubility of $2 \mathrm{~g}$ having methoxyethoxy groups was different from the other polymers; $2 \mathrm{~g}$ was completely soluble in $\mathrm{CHCl}_{3}$, and partially soluble in toluene, tetrahydrofuran and dimethylsulfoxide.

\section{Gas permeation property}

Freestanding membranes of polymers $2 \mathbf{a}-\mathbf{e}$ were initially prepared by solution casting, but no tough membranes were obtained for the gas permeability measurement. Thus, we attempted to prepare the membrane by the hot-press method. Our previous study has reported that the membrane prepared by hot-press has a more dense structure than the membrane prepared by solution casting. ${ }^{34}$ Therefore, the hotpress method may afford tougher membranes. Freestanding membranes of $\mathbf{2} \mathbf{b}-\mathbf{d}$ could be obtained, and their gas permeability could be studied. However, the membranes of $\mathbf{2} \mathbf{a}$ and $\mathbf{2 e}$ remained weak and could not be used for the gas permeability measurement. This result is because $\mathbf{2} \mathbf{b}-\mathbf{d}$ were crystalline polymers, while $\mathbf{2 a}$ and $\mathbf{2 e}$ were amorphous polymers. The membrane of $\mathbf{2} \mathbf{f}$ was not obtained because its melting temperature was lower than room temperature.

Table 3 lists the density, permeability coefficients and ratios of the coefficients for the $\mathrm{O}_{2} / \mathrm{N}_{2}$ and $\mathrm{CO}_{2} / \mathrm{N}_{2}$ ratios of membranes $2 \mathbf{b}-\mathbf{d}$ at $25^{\circ} \mathrm{C}$. The nitrogen permeability coefficient $\left(P \mathrm{~N}_{2}\right)$ of the membrane of 2b was 10.3 barrers, which is one order of magnitude larger than those of hexyl ester-substituted poly( $p$-phenylene), which we reported previously $\left(P \mathrm{~N}_{2}=1.55\right.$ barrer), and conventional glassy polymers, such as low-density-polyethylene and polystyrene. ${ }^{35}$ In the case of ester-substituted poly( $p$-phenylene $)$ s, the gas permeability increased as the alkyl chains lengthened $\left(P \mathrm{~N}_{2}=1.55\right.$ barrer for hexyl, 4.78 barrer for octyl, 10.8 barrer for decyl). However, the gas permeability coefficients of $\mathbf{2 c}$ were lower than those of $\mathbf{2 b}$, and the gas coefficients of $\mathbf{2 d}$ were slightly higher than those of $\mathbf{2} \mathbf{b}$. The densities of the membranes increase in the order of $\mathbf{2} \mathbf{d}<\mathbf{2} \mathbf{b}<\mathbf{2}$ c. During gas permeation through a nonporous membrane, a gas molecule permeates in the amorphous regions, not in the crystalline regions. Therefore, a polymer with high crystallinity generally shows a lower gas permeability than a polymer with low crystallinity or an amorphous polymer. The variation of gas permeability between $\mathbf{2 b}-\mathbf{d}$ is thought to be dependent on their crystallinity; thus, the tendency of the side chain is not the same as that for amorphous estersubstituted poly( $p$-phenylene)s. However, the gas permeability of $\mathbf{2} \mathbf{b}-\mathbf{d}$ was higher than that of amorphous poly( $p$-phenylene)s bearing ester substituents, even though $\mathbf{2 b}-\mathbf{d}$ were crystalline. This result suggests that compared with ester substituents, alkoxy substituents increase the gas diffusion in the amorphous region.

The separation factors of $\mathbf{2} \mathbf{b}-\mathbf{d}$ are comparable to each other, and the $P \mathrm{O}_{2} / P \mathrm{~N}_{2}$ and $P \mathrm{PO}_{2} / \mathrm{PN}_{2}$ values are $2.48-2.53$ and $11.6-12.4$, respectively. Generally, polymer membranes that are more gas permeable have less selectivity and vice versa because the growing diffusivity of the gas molecules weakens the molecular-sieve effect. Polymer 2c showed low gas permeability compared with $\mathbf{2 b}$ and $2 \mathbf{d}$, but the separation factor of $\mathbf{2 c}$ was nearly identical to that of $\mathbf{2 b}$ and $\mathbf{2 d}$. This result can be explained if the low permeability of $2 \mathrm{c}$ is attributable not to the decrease of diffusivity but to the decrease of the permeation area.

\section{CONCLUSION}

The polymerization of ether-substituted p-dibromobenzene (1a-i) with $\mathrm{Ni}$ (dppe $\mathrm{Cl}_{2}$ was demonstrated, and the gas permeability of the freestanding membranes of ether-substituted poly( $p$-phenylene)s was revealed. The three types of polymers with hexyloxy, octyloxy, decyloxy groups as the side chains $(\mathbf{2} \mathbf{b}-\mathbf{d})$ were crystalline polymers at room temperature, and they could afford freestanding membranes by the hot-press method. The gas permeability of $\mathbf{2} \mathbf{b}-\mathbf{d}$ was higher than that of amorphous poly( $p$-phenylene)s having ester groups, despite the crystallinity of $\mathbf{2} \mathbf{b}-\mathbf{d}$.

\section{ACKNOWLEDGEMENTS}

This research was supported in part by a grant-in-aid for scientific research from the Ministry of Education, Science, Culture and Sports, Japan (No. 25810071).

1 Baker, R. W. \& Low, B. T. Gas separation membrane materials: a perspective. Macromolecules 47, 6999-7013 (2014).

2 Pinnau, I. \& Freeman, B. D. Advanced Materials for Membrane Separation, ACS Symposium Series 876, (American Chemical Society, Washington DC, USA, 2004).

3 Tsujita, Y. Gas sorption and permeation of glassy polymers with microvoids. Prog. Polym. Sci. 28, 1377-1401 (2003).

4 Nunes, S. P. \& Peinemann, K. V. Membrane Technology in the Chemical Industry, (Wiley, New York, NY, USA, 2001).

5 Pandey, P. \& Chauhan, R. S. Membranes for gas separation. Prog. Polym. Sci. 26, 853-893 (2001).

6 Nagai, K., Masuda, T., Nakagawa, T., Freeman, B. D. \& Pinnau, I. Poly[1-(trimethylsi$|y|)-1$-propyne] and related polymers: synthesis, properties, and functions. Prog. Polym. Sci. 26, 721-798 (2001).

7 Aoki, T. Macromolecular design of permselective membranes. Prog. Polym. Sci. 24, 951-993 (1999).

8 Sakaguchi, T., Yumoto, K., Shida, Y., Shiotsuki, M., Sanda, F. \& Masuda, T. Synthesis, properties, and gas permeability of novel poly(diarylacetylene) derivatives. J. Polym. Sci. A Polym. Chem. 44, 5028-5038 (2006).

9 Tsuchihara, K., Masuda, T. \& Higashimura, T. Polymerization of silicon-containing diphenylacetylenes and high gas permeability of the product polymers. Macromolecules 25, 5816-5820 (1992).

10 Ismail, A. F. \& David, L. I. B. A review on the latest development of carbon membranes for gas separation. J. Membr. Sci. 193, 1-18 (2001).

$11 \mathrm{Kim}$, Y. K., Park, H. B. \& Lee, Y. M. Preparation and characterization of carbon molecular sieve membranes derived from BTDA-ODA polyimide and their gas separation properties. J. Membr. Sci. 255, 265-273 (2005).

12 Budd, P. M., Msayib, K. J., Tattershall, C. E., Ghanem, B. S., Reynolds, K. J., McKeown, N. B. \& Fritseh, D. Gas separation membranes from polymers of intrinsic microporosity. J. Membr. Sci. 251, 263-269 (2005).

13 Budd, P. M., Ghanem, B. S., Makhseed, S., McKeown, N. B. \& Msayib, K. J. Polymers of intrinsic microporosity (PIMs): robust, solution-processable, organic nanoporous materials. Chem. Commum. 230-231 (2004).

14 Kaeriyama, K. in Photonic Polymer Systems (eds Wise D. L., Knek G. E., Trantolo D. J., Cooper T. M., Gresser J. D.) Synthesis and properties of poly(p-phenylene) and its derivatives 33 (Marcel Dekker, New York, NY, USA, 1998).

15 Kovacic, P. \& Jones, M. B. Dehydro coupling of aromatic nuclei by catalyst-oxidant systems: poly(p-phenylene). Chem. Rev. 87, 357-379 (1987).

16 Yamamoto, T. Synthesis of $\pi$-conjugated polymers by organometallic polycondensation. Bull. Chem. Soc. Jpn 83, 431-455 (2010).

17 Yamamoto, T., Osakada, K., Wakabayashi, T. \& Yamamoto, A. Nickel and palladium catalyzed dehalogenating polycondensation of dihaloaromatic compounds with zinc. A new route to poly(2,5-thienylene)s and poly(1,4-phenylene). Makromol. Chem., Rapid. Commun. 6, 671-674 (1985). 
18 Sakaguchi, T., Tominaga, S. \& Hashimoto, T. Synthesis and gas permeability of ester substituted poly(p-phenylene)s. Polymer 52, 2163-2169 (2011).

19 Ueda, M., Abe, T. \& Awano, H. Synthesis of poly(2,5-dialkoxyphenylene). Macromolecules 25, 5125-5130 (1992).

20 Okada, T., Ogata, T. \& Ueda, M. Synthesis and characterization of regiocontrolled poly (2,5-di- $n$-butoxy-1,4-phenylene) by oxovanadium-catalyzed oxidative coupling polymerization. Macromolecules 29, 7645-7650 (1996).

21 Bai, W. B. \& Zhan, C. M. Regioregular poly( $p$-alkoxyphenylene)s prepared from facile solid-state oxidative coupling polymerization. Chem. Lett. 34, 924-925 (2005).

22 Yokozawa, T. \& Yokoyama, A. Chain-growth condensation polymerization for the synthesis of well-defined condensation polymers and $\pi$-conjugated polymers. Chem. Rev 109, 5595-5619 (2009).

23 Miyakoshi, R., Yokoyama, A. \& Yokozawa, T. Development of catalyst-transfer condensation polymerization. Synthesis of $\pi$-conjugated polymers with controlled molecular weight and low polydispersity. J. Polym. Sci. A: Polym. Chem 46, 753-765 (2008)

24 Lanni, E. L. \& McNeil, A. J. Mechanistic studies on Ni(dppe) $\mathrm{Cl}_{2}$-catalyzed chain-growth polymerizations: evidence for rate-determining reductive elimination. J. Am. Chem. Soc. 131, 16573-16579 (2009).

25 Umezawa, K., Oshima, T., Yoshizawa-Fujita, M., Takeoka, Y. \& Rikukawa, M. Synthesis of hydrophilic-hydrophobic block copolymer ionomers based on polyphenylenes. ACS Macro. Lett. 1, 969-972 (2012)

26 Miyakoshi, R., Shimono, K., Yokoyama, A. \& Yokozawa, T. Catalyst-transfer polycondensation for the synthesis of poly( $p$-phenylene) with controlled molecular weight and low polydispersity. J. Am. Chem. Soc. 128, 16012-16013 (2006).
27 Moy, C. L., Kaliappan, R. \& McNeil, A. J. Aryl trihydroxyborate salts: thermally unstable species with unusual gelation abilities. J. Org. Chem. 76, 8501-8507 (2011).

28 Huang, Z. -P., Huang, G. -S. \& Chen, S. -A. Deep blue electroluminescent phenylenebased polymers. Synth. Met. 157, 863-871 (2007).

29 Kuster, S. \& Geiger, T. Strategies and investigations on bridging squaraine dye units. Dyes Pigm. 95, 657-670 (2012).

30 Nemoto, N., Watanabe, Y., Umemiya, J. \& Otomo, Y. Synthesis and characterization of poly(tetramethyl-1,4-silphenylenesiloxane) derivatives with oxyethylene substituent on phenylene moiety. Polym. Bull 57, 661-670 (2006).

31 Keegstra, E. M. D., Huisman, B. -H., Paardekooper, E. M., Hoogesteger, F. J., Zwikker, J. W., Jenneskens, L. W., Kooijman, H., Schouten, A., Veldman, N. \& Spek, A. L. 2,3,5,6-Tetraalkoxy-1,4-benzoquinones and structurally related tetraalkoxy benzene derivatives: synthesis, properties and solid state packing motifs. J. Chem. Soc. Perkin Trans. 2, 229-240 (1996).

32 Sakaguchi, T., Sato, M. \& Hashimoto, T. Synthesis of silyl-disubstituted poly (p-phenylenevinylene) membranes and their gas permeability. Polymer 54, 2272-2277 (2013)

33 Kwak, G., Minakuchi, M., Sakaguchi, T., Masuda, T. \& Fujiki, M. Poly(diphenylacetylene) bearing long alkyl side chain via silylene linkage: its lyotropic liquid crystallinity and optical anisotropy. Chem. Mater. 19, 3654-3661 (2007).

34 Sakaguchi, T., Koide, Y. \& Hashimoto, T. Synthesis of membranes of poly(vinyl ether)s and their gas permeability. J. Appl. Polym. Sci. 114, 2339-2343 (2009).

35 Pauly S. in Polymer Handbook (eds Brandrup J., Immergut E. H., Grulke E. A ) Permeability and diffusion data VI-545-VI-562, (Wiley, New York, NY, USA, 1998). 